\title{
Monocyte diapedesis through an in vitro vessel wall construct: inhibition with monoclonal antibodies to thrombospondin
}

\author{
Andres R. Huber,, Susan Ellis, ${ }^{\star}$ Kent J. Johnson, ${ }^{\dagger}$ Vishva M. Dixit, ${ }^{\dagger}$ and James Varani ${ }^{\dagger}$ \\ ${ }^{*}$ Department of Internal Medicine, Emory University School of Medicine, Atlanta, Georgia, and ${ }^{\dagger}$ Department of Pathology, \\ The University of Michigan Medical School, Ann Arbor
}

\begin{abstract}
Human peripheral blood monocytes were examined for migration across an endothelial cell monolayer in an in vitro vessel wall construct. Few monocytes invaded in the absence of a chemotactic gradient, despite significant adhesion to the endothelial monolayer. However, the addition of zymosan-activated human plasma to the lower compartment, to create a chemotactic gradient across the vessel wall, resulted in significantly enhanced monocyte migration. Pretreatment of the monocytes with monoclonal antibodies to thrombospondin (TSP) dramatically inhibited monocyte diapedesis into the vessel wall. The same treatment inhibited monocyte adhesion to endothelial cells in two-dimensional monolayer cultures as well as in vessel wall constructs (no chemotactic gradient). Of interest, however, the monoclonal antibodies had no inhibitory effect on monocyte migration into collagen gels devoid of endothelial cells in response to the same chemotactic gradient, suggesting the importance of TSP in monocyte-endothelial cell interactions. Monoclonal antibodies to fibronectin and normal mouse immunoglobulin $G$ did not inhibit migration in this model of a vessel wall. Furthermore, monoclonal antibodies to TSP showed no inhibition of human peripheral blood neutrophil migration. Previous studies have shown that monocytes synthesize TSP and express this moiety on their surface. The present data suggest that monocytes may utilize TSP to interact with endothelial cells lining the vessel wall during diapedesis. J. Leukoc. Biol. 52: 524-528; 1992.
\end{abstract}

Key Words: monocytes $\cdot$ diapedesis $\cdot$ thrombospondin

\section{INTRODUCTION}

Thrombospondin (TSP) is a high-molecular-weight glycoprotein that is synthesized by platelets and stored in the $\alpha$ granules [1,2]. It is released during activation, binds to the platelet cell surface, and participates in the secondary phase of platelet aggregation [3]. A role for TSP in platelet interaction with monocytes has also been demonstrated [4]. Although this may be due to platelet TSP interacting with specific TSP receptors on the monocyte surface, monocytes are also known to synthesize TSP $[5,6]$ and a role for monocyte TSP cannot be completely ruled out. We demonstrated that monocyte interaction with squamous epithelial cells was also dependent on TSP [6]. Monocytes were able to bind to and kill undifferentiated squamous epithelial cells, which expressed high levels of TSP-binding activity. TSP receptor expression was decreased during differentiation and monocytes were less effective in binding to and killing these cells. Furthermore, antibodies to TSP inhibited monocyte killing of the undifferentiated epithelial cells. The present study continues efforts to understand the role of TSP in monocyte function. We show here that monoclonal antibodies to TSP inhibit monocyte adhesion to endothelial cells and migration through an in vitro construct of a vascular wall.

\section{MATERIALS AND METHODS}

\section{Endothelial cells}

Human umbilical vein endothelial cells were obtained as described by Gimbrone [7]. Culture medium consisted of M199 (Gibco Laboratories, Grand Island, NY) supplemented with $20 \%$ pooled human serum, $100 \mathrm{U} / \mathrm{ml}$ penicillin, $50 \mu \mathrm{g} / \mathrm{ml}$ streptomycin, $0.25 \mu \mathrm{g} / \mathrm{ml}$ amphotericin $\mathrm{B}$, and $75 \mu \mathrm{g} / \mathrm{ml}$ endothelial cell growth supplement (Collaborative Research, Boston, MA). In this study only primary endothelial cell cultures were used.

\section{Monocytes and neutrophils}

Human peripheral blood monocytes were isolated from anticoagulated blood (EDTA, $5 \mathrm{mM}$ ). The platelet-rich plasma was separated by centrifugation at $23^{\circ} \mathrm{C}$ at $125 \mathrm{~g}$ for $20 \mathrm{~min}$. All further procedures were carried out at $4^{\circ} \mathrm{C}$ unless otherwise specified. The pellet was diluted with 1:1 volume Seligman's balanced salt solution lacking magnesium and calcium (SBSS) and centrifuged at $125 \mathrm{~g}$ for $20 \mathrm{~min}$. This procedure was repeated once again, after the pellet was discharged. The cells were then resuspended in SBSS containing $0.3 \mathrm{mM}$ EDTA, layered on top of Ficoll-Hypaque, and centrifuged at $800 \mathrm{~g}$ for $25 \mathrm{~min}$ at $23^{\circ} \mathrm{C}$. The aliquot containing the mononuclear cells at the gradient interface was diluted with SBSS and pelleted. The mononuclear cells were then subjected to two sequential incubations in fresh human plasma containing EDTA to remove monocyte-associated platelets $\left(10 \mathrm{ml}\right.$ of plasma was used per $2 \times 10^{8}$ mononuclear cells in $15-\mathrm{ml}$ polyethylene conical tubes for each incubation). Mononuclear cells were recovered by centrifugation and, while still suspended in plasma-EDTA, then fractionated using Nycodenz gradients (Nycodenz monocytes, Accurate Chemical and Scientific Corporation, Westbury, New York). The monocyte fraction obtained at the interface was depleted of all granulocytes and lymphocytes and contained monocytes of greater than $90 \%$ purity and greater than $95 \%$ viability. After washing, monocytes were resuspended in Hanks' balanced salt solution (HBSS) containing 20\% heat-

\footnotetext{
Abbreviations: Fn, fibronectin; IgG, immunoglobulin G; HBSS, Hanks' balanced salt solution; mAb, monoclonal antibody; SBSS, Seligman's balanced salt solution; TSP, thrombospondin.

Reprint requests: James Varani, Department of Pathology, The University of Michigan Medical School, 1301 Catherine Road, Box 0602, Ann Arbor, MI 48109
}

Received February 13, 1992; accepted July 1, 1992. 
inactivated plasma at the specified concentration and kept on ice until used.

Human peripheral blood neutrophils were also used in these experiments. Heparinized blood $(10 \mathrm{U} / \mathrm{ml})$ was obtained from healthy adult volunteers. Neutrophils were separated by dextran sedimentation and density-gradient centrifugation using Ficoll-Hypaque. The cells obtained were approximately $98 \%$ neutrophils.

\section{Anti-TSP antibodies}

Monoclonal antibodies against three different domains of the TSP molecule were produced as described in past publications [3, 8, 9]. One of the monoclonal antibodies (designated A2.5) binds to the heparin-binding site of the TSP molecule. The second monoclonal antibody (designated C6.7) binds to the large globular domain of the TSP molecule at the $\mathrm{COOH}$ terminus and blocks platelet aggregation. The third monoclonal antibody (designated D4.6) binds to the fibrinogen-binding domain of the TSP molecule. For these studies, the three antibodies were mixed in equal concentrations and the total dosage used for the mixture of the three antibodies was 5-50 $\mu \mathrm{g}$. Prior to use, the antibody preparations were examined for endotoxin contamination using the Limulus amebocyte lysate assay (E-toxate; Sigma Chemical Co., St. Louis, MO) and found to contain less than 0.02 $\mathrm{ng} / \mathrm{ml}$.

As controls, three commercially available antifibronectin mouse monoclonal antibodies were used. All were obtained from Telios Pharmaceuticals (San Diego, CA). The three antibodies were to the heparin-binding site (clone 1), the cell attachment site (clone 2), and the gelatin-binding site (clone 3) of fibronectin. All were immunoglobulin G (IgG), antibodies and all three were used at a 1:100 (v/v) final dilution. Normal mouse IgG served as an additional control.

Both monocytes and neutrophils were preincubated in HBSS with the indicated antibodies or control IgG at the indicated concentrations for $30 \mathrm{~min}$ at ambient temperature just before the addition to the vessel wall constructs or collagen matrices.

\section{Construct of the vessel wall model}

The vessel wall construct consisted of a monolayer of human umbilical vein endothelial cells residing on a (rat tail) collagenous matrix. Briefly, $2 \mathrm{mg}$ of hydrated collagen solution was added to $3-\mu \mathrm{m}$ (pore size) polycarbonate filters placed in double-chamber culture dishes (Transwell 3414; Costar, Cambridge, MA) and allowed to gel. The gels were then preincubated for $2 \mathrm{~h}$ with culture medium and then seeded with human umbilical vein endothelial cells $\left(5 \times 10^{4} /\right.$ well $)$ in endothelial cell growth medium. The endothelial cells were allowed to grow for 19-21 days with fresh culture medium added at 3-day intervals. During this time, the endothelial cells produced a basement membrane that closely resembled the naturally occurring vascular basement membrane as indicated by biochemical and ultrastructural criteria. The construction and characterization of the in vitro vessel wall and its use to investigate neutrophil migration have been described in detail $[10,11]$.

\section{Monocyte transmigration through the vessel wall construct}

Monocytes were examined for ability to migrate through the vessel wall construct under the influence of a chemotactic stimulus. Monocytes $\left(1 \times 10^{6}\right.$ cells in $1 \mathrm{ml}$ of HBSS containing $20 \%$ heat-inactivated autologous plasma) were added to the upper (endothelial cell) surface of the vessel wall construct. To the lower chamber was added either normal human plasma ( $600 \mu \mathrm{l}$ in $3 \mathrm{ml}$ of HBSS) or zymosan-activated human plasma, prepared as described previously [12], to establish a chemotactic gradient across the vessel wall construct. The monocytes were allowed to migrate for $4 \mathrm{~h}$, after which the nonattached cells were removed from the endothelial surface. The endothelial cells were gently washed three times with an EDTA-containing buffer. The washes were pooled with the nonattached cells, centrifuged at $300 \mathrm{~g}$, resuspended in $500 \mu \mathrm{l}$ of buffer, and counted in triplicate using an electronic counter. From this, the number and percentage of cells attached to the vessel wall were determined. Then the leading-front method [13] was used to determine the distance traversed by the migrating cells in $4 \mathrm{~h}$ (five random fields per construct at $100 \times$ on an inverted phase microscope were assessed). In addition, certain cultures were fixed and cut in cross section, stained with hematoxylin and eosin, and photographed. In some experiments, neutrophils were used in place of monocytes. Migration through the vessel wall construct with these cells was studied in exactly the same way as with monocytes.

\section{RESULTS}

\section{Monocyte adhesion to endothelial cells}

In the first series of experiments we examined the ability of monoclonal anti-TSP antibodies to inhibit monocyte adhesion to endothelial cells in monolayer culture. Human peripheral blood monocytes were obtained as described in Materials and Methods and then incubated in polypropylene tubes with either the monoclonal antibodies to TSP (50 $\mu \mathrm{g}$ total of antibody mixture per $1 \times 10^{6}$ cells in $1 \mathrm{ml}$ of buffer) or $50 \mu \mathrm{g}$ of normal mouse IgG. After $30 \mathrm{~min}$, the cells and antibody were added to the endothelial cells. The percentage of adherent cells was determined $1 \mathrm{~h}$ later by removing and counting the nonattached cells. In the absence of antibody, $57 \pm 3 \%$ of the cells attached during this period, whereas only $26 \pm 2 \%$ attached in the presence of the monoclonal antibody to TSP. A total of $50 \mu \mathrm{g}$ of antibody mixture was the highest amount used. A lower amount (5 $\mu \mathrm{g}$ total) was used but proved to be ineffective at blocking adhesion (not shown).

\section{Monocyte migration through the vessel wall construct}

We next examined monocytes for ability to migrate through the vessel wall construct under the influence of a chemotactic gradient. Migration studies were carried out as described in Materials and Methods. Data from several studies are summarized in Table 1. It can be seen that although there was little invasion across the endothelial cell monolayer, despite significant adhesion in the absence of a chemotactic gradient, the inclusion of zymosan-activated plasma in the lower well produced a strong signal for migration. This was true not only for monocytes but also for neutrophils. This is not surprising because the chemotactic peptide produced upon zymosan activation of human plasma (e.g., C5a) is known to be chemotactic for both neutrophils and monocytes [12]. Table 1 also shows that preincubation of monocytes with the anti-TSP monoclonal antibodies ( $50 \mu \mathrm{g}$ total) significantly inhibited (approximately 50\%) monocyte migration through the vessel wall construct in comparison to a control antibody, as well as adhesion to the monolayer $(\sim 50 \%)$. In other experiments (Table 2), preincubation of monocytes with three 
TABLE 1. Effects of Monoclonal Antibodies to TSP on Monocyte Migration in the In Vitro Vessel Wall Constructe

\begin{tabular}{|c|c|c|c|c|}
\hline Treatment group & $\begin{array}{l}\text { Leading front } \\
(\mu \mathrm{m})\end{array}$ & $\begin{array}{l}\text { Vessel wall-associated } \\
\text { monocytes } \\
\left(\times 10^{3}\right)\end{array}$ & $\begin{array}{l}\text { Vessel wall-associated } \\
\text { monocytes } \\
(\%)\end{array}$ & $\begin{array}{c}\text { Inhibition } \\
(\%)\end{array}$ \\
\hline $\begin{array}{l}\text { Normal human plasma } \\
\quad+\text { anti-TSP } \\
+ \text { control IgG }\end{array}$ & $\begin{array}{l}75 \pm 23 \\
70 \pm 20 \\
72 \pm 28\end{array}$ & $\begin{array}{l}599 \pm 35 \\
316 \pm 41 \\
612 \pm 51\end{array}$ & $\begin{array}{l}60 \pm 3.5 \\
32 \pm 4.1 \\
61 \pm 5.1\end{array}$ & $\begin{array}{l}- \\
49 \\
-1\end{array}$ \\
\hline $\begin{array}{l}\text { Zymosan-activated human plasma } \\
\quad+\text { anti-TSP } \\
\quad+\text { control IgG }\end{array}$ & $\begin{array}{l}405 \pm 21 \\
185 \pm 10 \\
411 \pm 27\end{array}$ & $\begin{array}{l}715 \pm 26 \\
375 \pm 33 \\
752 \pm 5.0\end{array}$ & $\begin{array}{l}72 \pm 2.6 \\
38 \pm 3.3 \\
75 \pm 5.0\end{array}$ & $\begin{array}{l}- \\
54 \\
-3\end{array}$ \\
\hline
\end{tabular}

${ }^{a}$ Invasion studies were carried out as described in Materials and Methods. Values shown represent means \pm standard deviations based on four separate paired experiments, each with four separate readings per data point. $P$ values $(t$-test) for control antibody vs. anti-TSP group in nonmigrating and migrating (zymosan-activated plasma) conditions are $<.05$ and $<.05$, respectively.

different antifibronectin monoclonal antibodies alone or in combination did not inhibit migration. The ability of monoclonal anti-TSP antibodies to inhibit monocyte migration is in contrast to their lack of effect on neutrophils. Neutrophils treated with the same concentration of anti-TSP migrated as well as control neutrophils (Table 2). Furthermore, a significant reduction in leading front (five farthest migrated monocytes) was observed with anti-TSP-treated cells. Cross sections through a vessel wall construct are shown in Figure 1. The effect of the chemotactic signal is shown in Figure 1A, where several mononuclear cells can be seen to have crossed the endothelial cell monolayer as well as the basement membrane and are located in the subendothelial collagenous matrix. It can be seen in Figure $1 \mathrm{~B}$ that fewer of the anti-TSP-treated monocytes have crossed the endothelial cell barrier.

In additional experiments, monocytes were examined for ability to migrate into the collagenous matrix without the endothelial cell monolayer on the surface. These experiments were carried out exactly the same way as when endothelial cells were present except that the monocytes were added directly to the surface of the collagen matrix. As shown in Table 3, the addition of a chemotactic signal to the lower well induced monocyte migration through the collagen matrix. Furthermore, it can be seen that preincubation of the cells with monoclonal anti-TSP antibodies did not interfere with invasion of this matrix.

\section{DISCUSSION}

TSP is known to mediate cell-substrate adhesion in a variety of cells [14-17], and previous studies from other laboratories $[4,18]$ and our own laboratory $[6,19]$ suggest that TSP may also play a role in monocyte interactions with other cells. These findings are extended here. The current studies show that monocyte migration through an in vitro vessel wall construct is significantly inhibited by monoclonal antibodies to TSP, whereas antibodies to fibronectin do not have this effect. The same antibodies to TSP also directly inhibit monocyte adhesion to endothelial cells in monolayer culture. Significant inhibition was observed when the endothelial cell monolayers were washed $1 \mathrm{~h}$ after addition of the monocytes. This suggests that failure of the anti-TSP-treated monocytes to cross the endothelial barrier in the vessel wall construct may be due, at least in part, to inhibition of adhesion. Adhesive interactions and subsequent migratory events are closely linked and modulating the adhesion of monocytes to the endothelial cells could be expected to contribute to altered migration.

How antibodies to TSP act to modulate monocyte migration through the vessel wall construct cannot be fully ascertained from the available data. Our working hypothesis is that the antibodies are effective by virtue of their binding to TSP on the monocyte surface and blocking subsequent events that are dependent on the presence of monocyte surface TSP. It

TABLE 2. Effects of Monoclonal Antibodies to Fibronectin on Neutrophil and Monocyte Migration Through Vessel Wall Explants

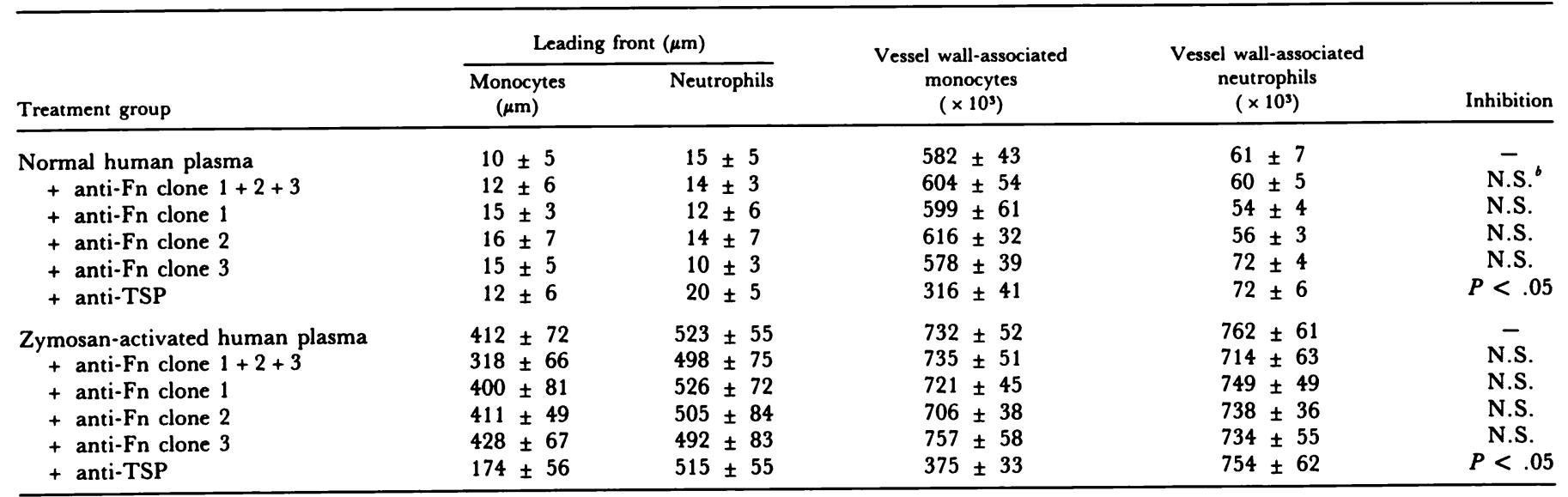

-Migration studies were carried out as described in Materials and Methods. Values shown represent means \pm standard deviations based on three separate experiments, each with four separate readings per data point. Clone 1 monoclonal antibody (mAb), to the heparin-binding site; clone $2 \mathrm{mAb}$, to cell attachment site; and clone $3 \mathrm{mAb}$, to gelatin-binding site. $P$ values ( $t$-test) for antifibronectin (anti-Fn) and anti-TSP vs. control antibody comparing vessel wall-associated monocytes are shown.

${ }^{b}$ N.S., not significant. 


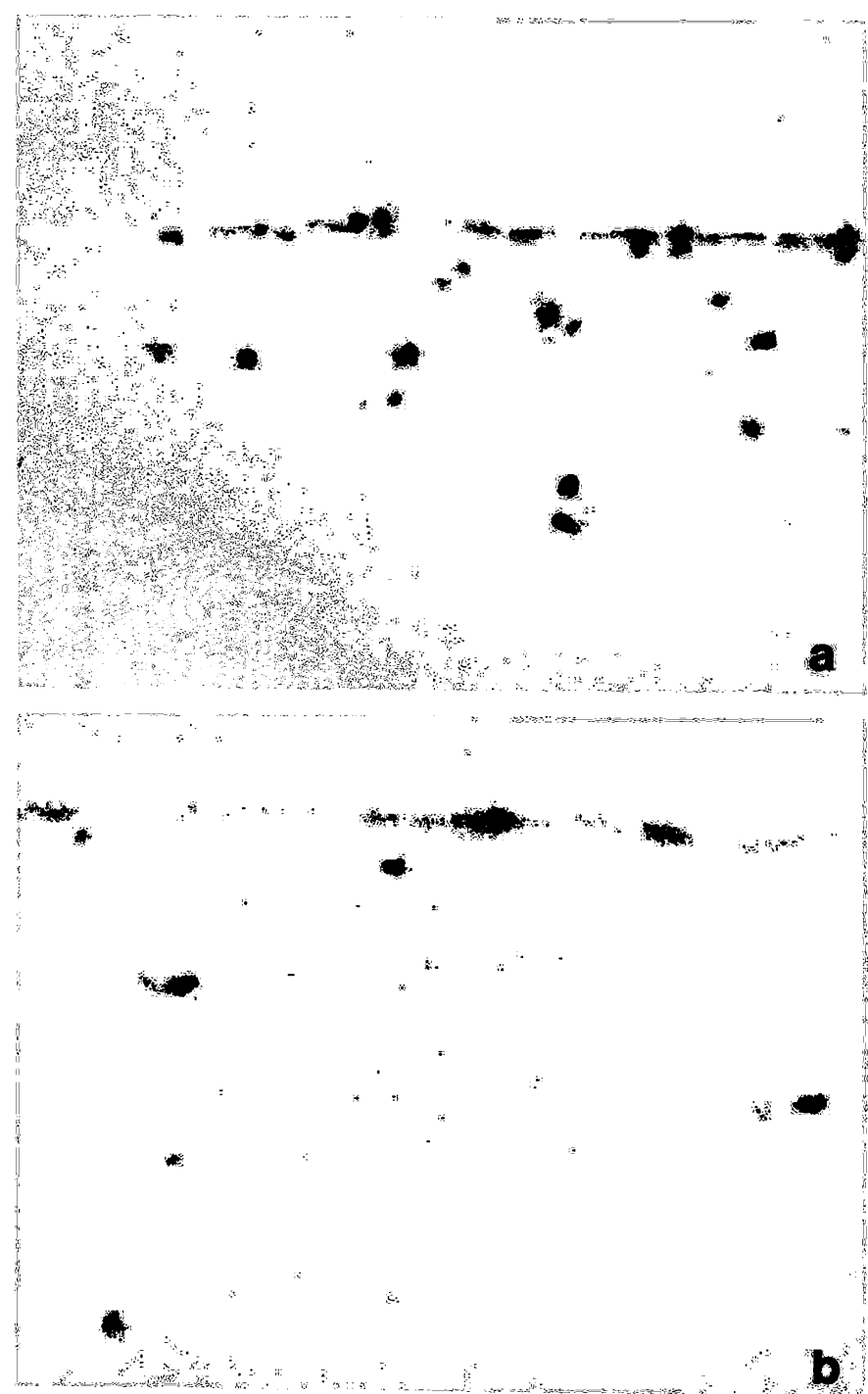

Fig. 1. Cross section through a vessel wall construct. Monocytes were placed on the endothelial cell surface and allowed to migrate in response to a chemotactic signal (A) or treated with antibodies to TSP and then allowed to migrate in response to the same chemotactic signal (B). Cells were fixed, sectioned, stained with hematoxylin and eosin, and photographed after $4 \mathrm{~h}$ of migration. X230.

is of interest in this regard that immunofluorescence staining of blood monocytes reveals very little detectable surface TPS $[5,6]$. However, TSP biosynthesis and surface expression are rapidly up-regulated when blood monocytes are incubated in monolayer culture. Increased expression correlates with the transition from a monocytoid cell to one with characteristics of mature macrophages. It has also been shown that TSP synthesis and expression are up-regulated in U937 cells following phorbol ester stimulation [19]. U937 cells are derived from an undifferentiated histiocytic tumor. Phorbol ester stimulation of the undifferentiated U937 cells results in the acquisition of characteristics reflective of mature monocytes. Thus, acquisition of surface TSP by monocytes occurs in parallel with acquisition of the capacity to leave the circulatory system and reside in extravascular compartments. The present data suggests that the onset of TSP expression may contribute to that capacity.

Alternatively, endothelial cells also express cell surface TSP [20] as well as TSP receptors [21]. Inhibition of monocyte adherence and migration might be due to antibody binding to these cells. Possibly, monocyte-endothelial cell interactions involve TSP and TSP receptors on the surface of both cells. Additional experiments will be necessary to distinguish between these possibilities as well as to determine which domains of TSP are critical mediators of the interaction between monocytes and endothelial cells. From the data obtained in studies on invasion of interstitial matrices (collagen matrix), one could conclude that the antibodies to TSP did not simply interfere with the monocytes' ability to migrate or respond to the chemotactic gradient. It rather seems that TSP is involved in monocyte-endothelial cell and basement membrane interactions.

The findings presented here indicate that monocyte (though not neutrophil) migration through an in vitro counterpart of an intact microvessel is influenced by monoclonal antibodies to TSP. This suggests a role of TSP in this process. Whether TSP plays a similar role in vivo is not known. It is interesting that past immunochemical studies have localized TSP in vivo to basement membranes at the dermal-epidermal junction and around blood vessels [22]. Thus, TSP appears to be physically present at sites where it would be expected if it functioned in monocyte diapedesis. How, specifically, TSP functions in diapedesis is not known, but several important events (e.g., initial adhesion, junctional penetration, or interaction with the subendothelial basement membrane) could be the target. Finally, it is of interost that the same monoclonal antibodies to TSP that were used here also dramatically reduce monocyte accumulation in the lungs of rats during the reverse passive Arthus reaction (K. J. Johnson, V. M. Dixit, and J. Varani, manuscript submitted for publication). This treatment dramatically reduces lung injury in a model that previous studies have shown to be dependent on both monocytes and neutrophils [23]. These data thus suggest the importance of threedimensional models of the vessel wall to study regulation of

TABLE 3. Effects of Monoclonal Antibodies to TSP on Monocyte Migration Through Collagen Matrices ${ }^{a}$

\begin{tabular}{|c|c|c|c|c|}
\hline $\begin{array}{l}\text { Normal human plasma } \\
\quad+\text { anti-TSP } \\
+ \text { control IgG }\end{array}$ & $\begin{array}{l}10 \pm 5 \\
15 \pm 5 \\
10 \pm 5\end{array}$ & $\begin{array}{l}47 \pm 25 \\
32 \pm 13 \\
42 \pm 20\end{array}$ & $\begin{array}{l}5 \pm 2.5 \\
3 \pm 1.3 \\
4 \pm 2.0\end{array}$ & $\begin{array}{l}- \\
\text { N.S. } \\
\text { N.S. }\end{array}$ \\
\hline $\begin{array}{l}\text { Zymosan-activated human plasma } \\
\quad+\text { anti-TSP } \\
\quad+\text { control IgG }\end{array}$ & $\begin{array}{l}445 \pm 10 \\
450 \pm 15 \\
440 \pm 20\end{array}$ & $\begin{array}{l}687 \pm 44 \\
655 \pm 40 \\
666 \pm 49\end{array}$ & $\begin{array}{l}69 \pm 4.4 \\
66 \pm 4.0 \\
67 \pm 4.9\end{array}$ & $\begin{array}{l}- \\
\text { N.S. } \\
\text { N.S. }\end{array}$ \\
\hline
\end{tabular}

${ }^{a}$ Migration studies were carried out as described in Materials and Methods. Values shown represent means \pm standard deviations based on four separate experiments, each with four separate readings per data point. $P$ values $(t$-test) for control antibody vs. anti-TSP in both normal human plasma and zymosanactivated plasma were not significant (N.S.) at $P<.05$. 
inflammation, as two-dimensional systems are unable to detect certain biologically important phenomena. Based on the data presented here and on our recent in vivo data, we suggest that anti-TSP may function to inhibit the accumulation and/or functioning of monocytes and, in doing so, inhibit subsequent monocyte-dependent events that contribute to the tissue injury observed in the acute inflammatory response.

\section{ACKNOWLEDGMENT}

This study was supported in part by the Jill Andrews Memorial Research Fund at Emory University and by American Cancer Society grant IM-432.

\section{REFERENCES}

1. Baenziger, N., Brodie, G., Majerus, P. (1971) A thrombinsensitive protein of human platelet membranes. Proc. Natl. Acad. Sci. USA 68, 240-243.

2. Baenziger, N., Brodie, G., Majerus, P. (1972) Isolation and properties of a thrombin-sensitive protein of human platelets. $J$. Biol. Chem. 247, 2723-2731.

3. Dixit, V.M., Harverstick, D.M., O'Rourke, K.M., Hennessy, S.W., Grant, G.A., Santoro, S.A., Frazier, W.A. (1985) Monoclonal antibodies against human thrombospondin inhibit platelet aggregation. Proc. Natl. Acad. Sci. USA. 82, 3472-3476.

4. Silverstein, R.L., Nachman, R.L. (1987) Thrombospondin binds to monocytes-macrophages and mediates platelet monocyte adhesion. J. Clin. Invest. 79, 862-874.

5. Jaffe, E.A., Ruggiero, J.T., Falcone, D.J. (1985) Monocytes and macrophages synthesize and secret thrombospondin. Blood 65, 79-84.

6. Riser, B.L., Mitra, R., Perry, D., Dixit, V.M., Varani, J. (1989) Monocyte killing of human squamous epithelial cells: role for thrombospondin. Cancer Res. 49, 6123-6129.

7. Gimbrone, M.A. (1978) Culture of vascular endothelium. Prog Hemost. Thromb. 3, 1-28.

8. Galvin, N.J., Dixit, V.M., O'Rourke, K.M., Santoro, S.A., Grant, G.A., Frazier, W.A. (1985) Mappings of epitopes for monoclonal antibodies against human platelet thrombospondin with electron microscopy and high sensitivity amino acid sequencing. J. Cell. Biol. 101, 1434-1441.

9. Dixit, V.M., Haverstick, D.M., O'Rourke, K.M., Hennessy, S.W., Grant, G.A., Santoro, S.A., Frazier, W.A. (1985) Effects of anti-thrombospondin monoclonal antibodies on the agglutination of erythrocytes and fixed, activated platelet by purified thrombospondin. Biochemistry 24, 4270-4278.
10. Huber, A.R., Weiss, S.J. (1989) Disruption of the subendothelial basement membrane during neutrophil diapedesis in an in vitro construct of a blood vessel wall. J. Clin. Invest. 83, $1122-1136$

11. Huber, A.R., Kunkel, S.L., Todd, R.F. Weiss, S.J. (1991) Regulation of transendothelial migration by endogenous interleukin-8. Science 254, 99-102.

12. Perez, H.D., Chenoweth, D.E., Goldstein, I.M. (1986) Attachment of human C5a des arg to its cochemotaxin is required for maximum expression of chemotactic activity. J. Clin. Invest. 78, 1589-1595.

13. Zigmond, S.H., Hirsch, J.G. (1973) Leukocyte locomotion and chemotaxis: new methods for evaluation and demonstration of a cell-derived chemotactic factor. J. Exp. Med. 137, 387-410.

14. Varani, J., Dixit, V.M., Fligiel, S.E.G., McKeever, P.E., Carey, T.E. (1986) Thrombospondin-induced attachment and spreading of human squamous carcinoma cells. Exp. Cell Res. 167, 376-390.

15. Roberts, D.D., Sherwood, J.A., Ginsburg, V. (1987) Platelet thrombospondin mediates attachment and spreading of human melanoma cells. J. Cell Biol. 104, 131-140.

16. Tuszynski, G.P., Rothman, V.L., Murphy, A., Seigler, K., Smith, S., Smiths, J., Karczewski, J., Knudsen, K.A. (1987) Thrombospondin promotes cell-substrate adhesion. Science 236, 1570-1573.

17. Varani, J., Nickoloff, B.J., Riser, B.L., Mitra, R.S., O'Rourke, K., Dixit, V.M. (1987) Thrombospondin-induced adhesion of human keratinocytes. J. Clin. Invest. 81, 1537-1544.

18. Silverstein, R.L., Asch, A.S., Nachman, R.L. (1989) Glycoprotein IV mediates thrombospondin-dependent plateletmonocyte and platelet-U937 cell adhesion. J. Clin. Invest. 84, 546-552.

19. Varani, J., Stoolman, L., Wang, T., Schuger, L., Flippen, C. Dame, M., Johnson, K.J., Todd, R.F., Ryan, U.S., Ward, P.A. (1991) Thrombospondin production and thrombospondinmediated adhesion in U937 cells. Exp. Cell Res. 195, 177-182.

20. McPherson, J., Sage, H., Bornstein, P. (1981) Isolation and characterization of glycoproteins secreted by aortic endothelial cells in culture. J. Biol. Chem. 256, 1130-1136.

21. Murphy-Ullrich, J.E., Mosher, D.F. (1987) Interactions of thrombospondin with endothelial cells: receptor-mediated binding and degradation. J. Cell Biol. 105, 1603-1609.

22. Wight, T.N., Raugi, G.J., Mumby, S.M., Bornstein, P. (1985) Light microscopic immunolocalization of thrombospondin in human tissues. J. Histochem. Cytochem. 33, 299-302.

23. Warren, J.S., Yabroff, K.R., Remick, D.G., Kunkel, S.L., Chensue, S.W., Kunkel, R.G., Johnson, K.J., Ward, P.A. (1989) Tumor necrosis factor participates in the pathogenesis of acute immune complex alveolitis in the rat. J. Clin. Invest. 89, 1873-1882. 